\title{
Ser docente: inspiración, pasión y perseverancia
}

\author{
Melchor Sánchez Mendiola
}

"Lo que el maestro es, es más importante que lo que enseña"

Karl Menninger

El tiempo pasa vertiginosamente y cuando nos damos cuenta ya estamos a fin de año y en el cierre de algunos ciclos. La Revista Digital Universitaria (RDU) pasó de la Dirección General de Cómputo y de Tecnologías de Información y Comunicación (DGTIC) de la Universidad Nacional Autónoma de México (UNAM) a la Coordinación de Desarrollo Educativo e Innovación Curricular (CODEIc) de la misma institución, en el primer semestre de 2017. En estos dos años y meses hemos vivido intensamente la preparación, edición y publicación de seis números anuales de la $R D U$, con todos los retos, satisfacciones, incertidumbres y sinsabores que implica la creación de una revista de divulgación científica de calidad y la integración dinámica de los diferentes eslabones del proceso. En 2017 llamamos a la etapa que iniciaba la Revista como una "Nueva época", en la que se generaron varios cambios en el formato, secciones y proceso editorial de la misma, lo que hizo posible mantener una publicación periódica del nivel que requiere la UNAm. En este lapso se ha consolidado la nueva imagen de la RDU, con una ampliación de los contenidos temáticos que han colocado a la revista en un nicho muy interesante, que la distingue de las demás revistas de divulgación científica.

Dol: http://doi.org/10.22201/codeic.16076079e.2019.v20n6.a0 
Este año hemos publicado seis números, 60 artículos, con la participación de más de 100 autores de 30 instituciones. En las estadísticas de consulta en línea, se han registrado 78.19\% más usuarios que el año pasado; durante el 2018 se tiene registro de 51,090 usuarios y en el 2019, de 91,038, de los cuales 35\% son hombres y 64\% mujeres, de entre 18 a 34 años principalmente. La revista está sana y vibrante, recibimos cada vez más manuscritos para el proceso de arbitraje y se está colocando como un referente importante en la divulgación de la ciencia en nuestro país.

Este número está dedicado a la docencia, como se podrá percatar el lector, con una vista somera a los contenidos: la emoción en la práctica docente, la formación de docentes en el uso de la tecnología, trayectorias docentes, una caracterización de los docentes de la UNAM, el arte en la docencia, la experiencia de nuestros cursos de educación basada en evidencias, entre otros temas. ¿Por qué el énfasis en docencia en una revista de divulgación científica? Principalmente porque la mayoría de las revistas de este tipo tocan escasa e intermitentemente temas educativos y porque de poco sirve la enorme inversión en ciencia, investigación y tecnología, si no va acompañada de reflexiones sobre el proceso educativo. A fin de cuentas, la educación es la misión central de las instituciones de educación media superior y superior (como su nombre lo dice), y es nuestro deber ético difundir ideas, experiencias y reflexiones sobre el rol del docente en la turbulenta y complicada sociedad moderna.

Los docentes de nuestra Universidad y del resto de las instituciones educativas conforman una amplia y heterogénea colectividad de comunidades: profesores de asignatura o de tiempo parcial, profesores titulares, profesoresinvestigadores, maestros, educadores, educadores profesionales, profesionales de la educación, maestros y doctores en educación, entre muchos otros. Esta pluralidad de personajes con diversas funciones, roles, culturas y necesidades hace que sea particularmente complejo comunicarse con ellos. Es por ello que decidimos dedicar este número de la RDu a la función docente, para ofrecer un amplio panorama de diversas aristas que impactan a nuestros profesores.

La educación es un campo tan amplio del saber y quehacer humano que, para algunos autores como John Dewey, "la educación es la vida misma". Bajo esta premisa cualquier persona puede enseñar, por lo menos de manera informal, pero los docentes universitarios tienen una gran cantidad de responsabilidades educativas formales. Si nos enfocamos en esta población, podemos identificar muchos roles que nos definen, como son: proveedor de información, generador de recursos educativos, planificadores, evaluadores, facilitadores, mentores, modelos de rol, entre otros. Los diversos papeles que jugamos durante el proceso de enseñanza y aprendizaje requieren apoyo institucional, recursos adecuados en las aulas y demás espacios educativos, formación docente de calidad en diferentes modalidades, entre muchas otras cosas, para contribuir al aprendizaje complejo de los estudiantes. 
Con frecuencia los retos que enfrentamos como docentes durante el proceso educativo son muchos y de gran magnitud, por lo que debemos desarrollar asertividad, resiliencia, tolerancia, inteligencia emocional, capacidad de improvisar, innovar y crear, entre muchas otras habilidades. ¿Por qué los docentes dedicamos una parte importante de nuestro tiempo y esfuerzo a enseñar y facilitar el aprendizaje de los estudiantes? Por muchas razones, entre ellas: porque es una manera de devolver a la sociedad lo que hemos aprendido; porque deseamos contribuir al desarrollo de las nuevas generaciones y poner nuestro granito de arena en su desarrollo; porque el enseñar nos permite aprender, recordemos que "enseñar es aprender dos veces" y "enseñar bien, es aprender dos veces bien"; porque nos genera motivación predominantemente intrínseca; porque se vuelve gradualmente parte integral de nuestra identidad profesional; y porque es energizante, nos da una intensa satisfacción personal, y se convierte en parte de nuestro legado en el transitorio paso por la vida. Bien dijo Justo Sierra, en 1910, que le corresponde al maestro: "saturar al hombre de espíritu de sacrificio, para hacerle sentir el valor inmenso de la vida social, para convertirlo en un ser moral en toda la belleza serena de la expresión".

Invito a nuestros amables lectores a explorar los contenidos de este número de la RDU dedicado a la docencia, para que incorporemos los conceptos vertidos en los artículos a nuestra práctica educativa. Como comenté al inicio de esta editorial, el tiempo pasa y las decisiones difíciles se tienen que tomar con fundamento en las circunstancias y el contexto. He decidido finalizar esta etapa como Editor en jefe de la revista, en virtud de que mis obligaciones académicas y de funcionario universitario se han visto incrementadas sustancialmente, y cada vez es más difícil dedicarle a la Rou el tiempo que requiere para mantener el nivel de calidad de la publicación. Por ello, este es el último número en el que tendré el rol de Editor, aunque continuaré en el Comité editorial y colaborando como árbitro y autor. ¡Felices lecturas!

\section{Cómo citar este artículo}

* Sánchez Mendiola, Melchor (2019). Ser docente: inspiración, pasión y perseverancia. Revista Digital Universitaria (RDU). Vol. 20, núm. 6 noviembrediciembre. Dol: http://doi.org/10.22201/codeic.16076079e.2019.v20n6.a0. 